\title{
El peso de las jerarquías sociales locales en el orden público: la guardia nacional chilena durante el gobierno de José Joaquín Prieto (1831-1841)/
}

\author{
The Weight of the Social and Local Hierarchies in the Public \\ Order: The Chilean National Guard During José Joaquín \\ Prieto's Government (1831-1841)
}

\author{
María Teresa Douzet Carafí \\ ORCID iD: http://orcid.org/0000-0002-5802-2849 \\ Universidad Católica de Temuco
}

\begin{abstract}
Desde comienzos de la década de 1830, la guardia nacional se convierte en el principal instrumento del gobierno del presidente José Joaquín Prieto Vial (1831-1841) para garantizar el orden público en la república de Chile. El objetivo de este artículo es mostrar que ello no responde solamente a la voluntad del ejecutivo que fomenta sus funciones defensiva y moralizadora, y en lograr acuerdos políticos para su desarrollo institucional, sino al papel de las jerarquías sociales locales que posibilitan la inserción sociopolítica territorial de la guardia nacional y su funcionamiento.
\end{abstract}

Palabras clave: Guardia Nacional; Orden Público; Jerarquías Sociales.

Since the beginning of the 1830's, the National Guard becomes the main instrument of President José Joaquín Prieto's (1831-1841) government to guarantee the public order in the Republic of Chile. The objective of this article is to show that this not only deals with the will of the executive power who encourages its defensive and moralizing functions, and achieves political agreements for its institutional development, but with the social and local hierarchies which allow a sociopolitical and territorial insertion of the National Guard and its functioning.

Keywords: National Guard; Public Order; Social Hierarchies.

Copyright: () 2017 CSIC. Este es un artículo de acceso abierto distribuido bajo los términos de una licencia de uso y distribución Creative Commons Attribution (CC-by) España 3.0. 


\section{Introducción}

La inestabilidad política e institucional que caracteriza a los gobiernos de la década de 1820, comienza con la abdicación del director supremo Bernardo O'Higgins en $1823^{1}$ y culmina con la guerra civil ${ }^{2}$ que estalla tras las elecciones presidenciales de $1829 .{ }^{3}$ La sucesión intermitente de presidentes de la república ${ }^{4}$ entre 1823 y 1831 , la implementación de tres constituciones (1822, 1823 y 1828), la fallida constitución federal de 1827 y el irregular funcionamiento del Congreso son síntomas de la incertidumbre y fragilidad política de aquellos años. Diversos factores contribuyen a dicho escenario, a saber, conflictos entre los poderes ejecutivo y legislativo, tensiones entre el gobierno central y las provincias que alcanza niveles críticos en $1825,{ }^{5}$ malestar de los uniformados por sueldos y pagos irregulares, ${ }^{6} \mathrm{y}$ posterior división —durante la contienda de 1829— entre los seguidores del general José Joaquín Prieto y del capitán general Ramón Freire, al mando del ejército restaurador de la constitución y del ejército constitucional, respectivamente. El fraccionamiento al interior de las filas militares, corola-

1 La presión política de las tres provincias —Coquimbo, Concepción y Santiago- conduce a su abdicación el 28 de enero de 1823. Salazar, 1991, 171.

2 El conflicto se extiende desde el 7 de noviembre de 1829 hasta el 17 de abril de 1830.

3 Si bien los escrutinios definen claramente una primera mayoría para presidente de la república no ocurre lo mismo para el cargo de vice presidente. Según el artículo 72 de la constitución del 1828 las cámaras, mayoritariamente pipiolas, deben dirimir entre las mayorías inmediatas que adhieren al peluconismo. Sin embargo, el Congreso objeta esta alternativa y procede a votar entre todos los candidatos restantes. Gana por un estrecho margen el candidato pipiolo. Los pelucones solicitan la repetición del procedimiento, pero la mayoría parlamentaria lo rechaza. Esta situación que irrita a la oposición se convierte en la oportunidad de los pelucones para alzarse contra el gobierno, para liderar la revolución. (Constitución de 1828, en Valencia Avaria, I, 161. Barros Arana, 2005, XV, 265-269).

4 Chile cuenta con presidente de la república desde 1826; hasta esta fecha la máxima investidura es de director supremo.

5 Este año comienza con bases políticas inciertas por la derogación de la carta de 1823 y con condiciones económicas deficitarias por la prolongada crisis de hacienda. El antagonismo y la falta de coordinación entre el poder ejecutivo y el legislativo no hace más que debilitar al primero. Ello se cruza con la tensión que se genera entre las provincias de Coquimbo y Concepción, y la de Santiago. Las primeras acusan que el cuerpo legislativo no es más que una asamblea santiaguina que hostiga a sus representantes, por lo que cada una retira a los suyos y organiza una asamblea provincial. Este desconocimiento tácito al gobierno central pone en evidencia la pérdida de unidad política y administrativa territorial de la capital frente a la autonomía provincial, y obliga al director supremo Ramón Freire a cerrar el Congreso, convocando a nuevas elecciones para estabilizar la situación. La crisis tiene su punto más álgido cuando ambas provincias deciden no enviar a sus representantes al Congreso que se reabre en septiembre de 1825. Salazar, 2005, 245-252. Heise González, 1978, 171. Errázuriz, 1935, 59-60.

6 El desorden institucional y el excesivo gasto de mantenimiento, insostenible para el erario nacional, definen nuevas líneas de acción para resolver los problemas estructurales y mejorar las condiciones laborales. El gobierno busca revertir la precaria situación del ejército a través de la Reforma militar de 1827. Barros Arana, 2005, XV, 132-150. 
rio de la división política de la elite chilena entre pelucones (conservadores) y pipiolos (liberales), ${ }^{7}$ es visto por el peluconismo vencedor de la batalla librada en los campos de Lircay —el 17 de abril de 1830_ como la causa del desorden público y expresión final del debilitamiento del gobierno pipiolo.

En respuesta a este periodo que la historiografía tradicional ha tildado de anarquía, ${ }^{8}$ las nuevas autoridades peluconas ${ }^{9} \mathrm{y}$, en particular, el gobierno del presidente José Joaquín Prieto y su ministro Diego Portales Palazuelos ${ }^{10}$ procuran el fortalecimiento del poder ejecutivo y la recuperación del orden público, que se alza como preciado valor de la sociedad chilena. ${ }^{11}$ Por una parte, la población, hastiada de las perturbaciones políticas, solo anhela la paz e incluso tolera cuotas de autoritarismo a cambio de seguridad, afirma el historiador liberal Diego Barros Arana, ${ }^{12}$ por la otra, el propio proyecto de Estado requiere de un orden institucionalizado. ${ }^{13}$ De allí que, en la primera mitad de la década de 1830, el presidente Prieto se jacte de la «feliz tranquilidad que gozamos», «la permanencia del orden», «el amor al orden», como un logro político del gobierno pelucón. ${ }^{14}$ No por acaso, la historiografía nacional, en particular la conservadora, ha ensalzado la relación entre Estado y orden como constitutiva de la estabilidad chilena. ${ }^{15}$

Ahora bien, el triunfo del general José Joaquín Prieto sobre el capitán general Ramón Freire en Lircay, exige a los primeros gobiernos pelucones la difícil tarea de administrar políticamente la victoria militar sobre los pipiolos. Ello requiere supeditar las filas castrenses del fraccionado ejército;

7 Al igual que en los siglos anteriores, en esta etapa de formación estatal solo los militares aseguran la administración del gobierno. Desde la Independencia en 1811 los uniformados han estado en la cima gubernamental, por ende, las cúpulas políticas coinciden o se vinculan con los altos mandos militares. De allí la relevancia política de la división interna entre Prieto y Freire, ambos de reconocida trayectoria militar. La adhesión del primero a O’Higgins y los aires pipiolos del segundo generan una animadversión personal que alcanza ribetes institucionales en la coyuntura de 1829 .

8 Ver, por ejemplo, Barros Arana, 2005, 430. Edwards, 1982, 58.

9 Vicepresidente de la república José Tomás Ovalle (1. ${ }^{\circ}$ de abril de 1830 a 8 de marzo de 1831), presidente accidental y presidente provisorio Fernando Errázuriz ( 8 de marzo a 22 de marzo de 1831 y 22 de marzo a 18 de septiembre de 1831, respectivamente); y presidente José Joaquín Prieto Vial (18 de septiembre de 1831 a 18 de septiembre de 1841).

10 Ministro del Interior y Relaciones Exteriores (6 de abril 1830 a 31 de agosto de 1831; 7 de noviembre a 6 de junio de 1837), ministro de Guerra y Marina (6 de abril a 25 de septiembre de 1830; 17 de enero a 31 de agosto de 1831; cargo nominal hasta el 31 de agosto de 1832; 21 de septiembre de 1835 a 6 de junio de 1837).

11 Sobre valoración del orden ver Stuven 1997 y 2000; Góngora, 1986.

12 Barros Arana, 2005, XV, 430.

13 Stuven, 2000, 44-45.

14 Discursos de apertura, 1858a, 8, 16 y 27, respectivamente.

15 Algunos de los principales exponentes son Ramón Sotomayor Valdés, Alberto Edwards, Francisco Antonio Encina y Bernardino Bravo Lira. 
en lo inmediato para evitar levantamientos que desestabilicen la instalación del nuevo gobierno, en el corto plazo para reequilibrar los poderes a favor del ejecutivo. La constitución de 1833 apuntará precisamente en esta dirección al establecer que los militares no deliberan y deben obediencia al gobierno. ${ }^{16}$

La sumisión de las armas es un requisito para la estabilidad institucional. ${ }^{17}$ Por esta razón, las autoridades proceden a despolitizar el ejército. ${ }^{18}$ Entre marzo y mayo de 1830, 126 oficiales son dados de baja, sin sueldo, ni indemnización. La cantidad es muy significativa para un contingente que no supera las 2.500 plazas. ${ }^{19}$ El gobierno castiga a militares díscolos de diversa graduación con exoneración, prisión, y destierro, incluido el capitán general Freire. ${ }^{20}$ La limpieza política de las filas es necesaria, pero insuficiente para garantizar que el ejército no se vuelva a sublevar. La solución es contrarrestar las armas del ejército con las armas de la guardia nacional, institución que tendrá una triple finalidad: subordinar el ejército, fortalecer el ejecutivo y garantizar la tranquilidad pública. ${ }^{21}$

¿De dónde surge la guardia nacional? El gobierno aprovecha los únicos recursos armados disponibles en la apremiante coyuntura de 1830: las antiguas milicias que se remontan a mediados del siglo XVI cuando la corona impone a conquistadores y primeros pobladores la obligación de defender la tierra y acudir al llamado del monarca. El deber miliciano de cargar armas se origina en la obligación del vecino encomendero de proteger la ciudad con sus propios recursos (armas, dependientes y animales) aunque no tenga preparación militar; en el caso del reino de Chile, principalmente frente al acecho indígena. ${ }^{22}$ Los milicianos, paisanos (civiles en lenguaje antiguo) apercibidos para cumplir con el deber de cargar armas, tienen una larga historia y amplia cobertura territorial, pero una precaria experiencia con el fusil. El entrenamiento militar es esporádico e insuficiente porque los instructores del ejército son escasos; exiguas son las armas, pertrechos, vestuario y cuarteles. ${ }^{23}$ Pese a las críticas por su ineficiencia militar y al recelo

16 Constitución de 1833, en Valencia Avaria, 1986, I, 194.

17 Brahms García, 2007, 135.

18 Vergara Quiroz, 1989, 104.

19 Salazar, 2005, 376.

20 Bravo Lira, 1989. Salazar, 2005. Encina, 1964.

21 La guardia nacional tiene una doble dependencia: administrativa y política del ministerio de guerra, técnica y estratégica del ejército, específicamente de la inspección general y de la comandancia general de armas.

22 Góngora 1951, 1970. Jara, 1971.

23 Oñat y Roa, 1953. 
de la «gente decente» temerosa de la plebe armada, el gobierno de Prieto, en particular el ministro Portales, se empeña en perfeccionar los inorgánicos cuerpos milicianos para transformarlos en cuerpos cívicos debidamente organizados, en un «recurso de seguridad», en palabras del ministro. ${ }^{24}$

Cabe destacar que pese al aporte de Portales, no se trata de una guardia nacional «portaliana» creada por el ministro. Aunque sea reconocido por el presidente Prieto como el «genio creador de la Milicia Cívica» y «jefe nato» de la institución; ${ }^{25}$ aunque se afirme que es el «el brazo, la cabeza y el corazón» ${ }^{26}$ de la institución; y aunque la historiografía se empeñe en adjetivarla «portaliana», lo cierto es que el ministro no crea nada. Solo reactiva y fortalece un antiguo mecanismo de seguridad que se sostiene en obligaciones, vínculos sociales y lógicas locales existentes, que bien sabe articular con las necesidades políticas y defensivas de la crisis de 1830 .

La guardia nacional es un tema presente en la historia política, electoral y militar de la primera mitad del siglo XIX, pero nunca es el principal. Pese a la importancia que la historiografía nacional da al problema del orden público y al Estado como su principal garante, son escasos los historiadores que se han abocado al estudio de la institución. En primer lugar, cabe destacar el artículo de Roberto Hernández Ponce que presenta la trayectoria histórica e institucional desde las milicias coloniales hasta la guardia nacional decimonónica. ${ }^{27} \mathrm{El}$ autor realiza un aporte pionero al contextualizar el desarrollo en términos legales, constitucionales, políticos y electorales, destacando los principales hitos que marcan su relación con el ejecutivo y el ejército.

En segundo lugar, Joaquín Fernández Abara discute los alcances y limitaciones del guardia nacional como soldado ciudadano. En un lúcido artículo establece que en el marco de construcción nacional (1820-30), la guardia nacional pasa a ser un medio de difusión del nacionalismo y republicanismo imperantes. Si bien los «defensores de la patria» se legitiman constitucionalmente como ciudadanos en la carta de 1828, el autor señala los obstáculos políticos, sociales y burocráticos para alcanzar una real conciencia política. En un trabajo posterior retoma la relación entre nacionalismo

24 Carta de Diego Portales a Antonio Garfias, Placilla de La Ligua, 4 de julio de 1835. Fariña, 2007, II, 633.

25 Prieto citado en Hernández Ponce, 1984, 85.

26 Urízar Garfias, Fernando, «Proyecto de Lei sobre Reforma de la Guardia Nacional. Presentado a la Cámara de Diputados por el Señor Don Fernando Urizar Garfias (1. a Parte)», El Comercio, Valparaíso, 21 junio 1850, 1.

27 Hernández Ponce, 1984. 
y guardia nacional afirmando que el Estado incurre en una retórica nacionalista y republicana para legitimar el reclutamiento miliciano; tarea difícil considerando la carga que significa el servicio para obreros y artesanos. ${ }^{28}$

Tanto Hernández Ponce como Fernández Abara dan luces sobre un punto central para este artículo, cual es el peso de las jerarquías sociales en la organización y funcionamiento de las jerarquías milicianas. El primero plantea que la guardia nacional refuerza la estructura social al consolidar las figuras de «coronel-patrón» y de «guardia nacional peón», asegurando con ello el orden, la guerra y las elecciones. El segundo advierte que las lealtades señoriales minan la difusión de una identidad nacional desde la guardia nacional. ${ }^{29} \mathrm{Si}$ bien reconocidos historiadores clásicos como Barros Arana y Alberto Edwards y contemporáneos como Sergio Grez Toso, Julio Pinto y Verónica Valdivia se refieren a la tutela/dominación de las elites (comandantes) sobre la plebe (tropa), lo cierto es que requiere una mayor reflexión. ${ }^{30}$

Con todo, a partir de la revisión de fuentes primarias y secundarias, este artículo establece la relevancia de las funciones defensiva y moralizadora, y de los acuerdos políticos en torno a la guardia nacional, que responden a tres problemas específicos: contrapeso frente al ejército, reconocimiento público y consenso al interior de las elites, y eficacia militar de los cuerpos cívicos, respectivamente. Pero a su vez plantea que estos serían estériles si no operara el mecanismo sociopolítico y territorial que resuelve el problema de la confiabilidad y legitimidad de esta «masa misma de ciudadanos, armados en defensa de las leyes y la nación», ${ }^{31}$ que cumple con el deber constitucional de cargar armas sin mayor conocimiento ni entrenamiento militar. Dicho mecanismo es el sostén de la guardia nacional que le permite, en definitiva, a los vecinos pudientes - y sus dependientes - colaborar en la función estatal de garantizar el orden público, sobre todo en territorios alejados geográfica y políticamente del poder central. Este punto es crucial para comprender cómo el Estado chileno, debilitado por una década de crisis y una guerra civil, sin la capacidad política y burocrática para asegurar la tranquilidad pública por sí solo, refuerza un vínculo estratégico con la «sociedad», con las elites locales en aras de un objetivo compartido. Este artículo se detiene en dicho vínculo que no ha sido abordado en profundidad por la historiografía chilena.

28 Fernández Abara, 2004 y 2005.

29 Hernández Ponce, 1984, 111-112. Fernández Abara, 2005.

30 Barros Arana, 2005, XV. Edwards, 1972. Grez Toso, 1997. Pinto y Valdivia, 2009.

31 Discursos de apertura, 1858a, 392. 


\section{Función defensiva: problema del contrapeso frente al ejército}

La subordinación de los militares al ejecutivo, en aras del reequilibrio de poderes, no es solo política sino fáctica: el gobierno de Prieto contrapesa las fuerzas del ejército con las fuerzas de la guardia nacional. Al respecto el historiador conservador Ramón Sotomayor Valdés sostiene que: «El ejército, instrumento por tanto tiempo de las facciones políticas, tuvo en la guardia cívica un contrapeso que debía disminuir con mucho su funesta influencia en la suerte de 1 os Gobiernos y de 1 os partidos» ${ }^{32}$ La imagen de un dique de contención ante posibles insurrecciones, levantamientos y motines es una idea reafirmada por la historiografía nacional..$^{33}$

La capacidad de la guardia nacional de servir como antemural atañe a su masificación y extensión territorial, es decir, a la cobertura del servicio. Ello es plausible porque las antiguas milicias superan con creces las filas de línea. ${ }^{34}$ La evidencia histórica del periodo $1830-50$ indica que el crecimiento de los cívicos es exponencial mientras el número de hombres de línea se mantiene prácticamente constante. En la apertura del Congreso Nacional de 1831, el ministro del Interior Portales informa sobre los adelantos de la guardia nacional y de sus 25.000 hombres..$^{35}$ Cuatro años más tarde la cifra asciende a $30.094,{ }^{36}$ mientras que por ley del año 1826 — confirmada en 1835 - ${ }^{37}$ los uniformados no pueden sobrepasar las 3.000 plazas. ${ }^{38} \mathrm{Al}$ finalizar la década, el Congreso dictamina que para 1840 el ejército permanente reducirá su tamaño a 2.116 efectivos ${ }^{39}$ De manera progresiva la guardia nacional suma 35.890 hombres en $1839,56.829$ en 1845 y 62.311 en $1850 .{ }^{40}$ Con todo, la institución crece un $148 \%$ en veinte años. Por lo

\footnotetext{
32 Sotomayor Valdés, 1954, 49-50.

33 Barros Arana, 2005, XV. Vergara Quiroz, 1989. Nunn, 1976. Grez Toso, 1997.

34 A modo de ejemplo, al estallar la independencia, los milicianos superan los 15.000 mientras que los militares no alcanzan las 2.000 plazas. Barros Arana, 2005, VII, 218. Encina, 1952, 531, 534.

35 Portales habla en nombre del presidente provisorio Fernando Errázuriz, «Sesión inaugural», Congreso Nacional, Santiago, $1^{\circ}$ de junio de 1831 (Letelier, 1899, XX, 32).

36 Discursos de apertura, 1858a, 336.

37 Prieto-Portales, Santiago, 29 de septiembre de 1835, Anexo 181, Cámara de Diputados, sesión 34, 30 de septiembre de 1835 (Letelier, 1902, XXIV, 172).

38 Blanco Encalada-Ovejero, Santiago, 30 de julio de 1826, Anexo 473, sesión 43, 17 de agosto de 1826 Congreso Nacional (Letelier, 1889, XII, 371).

39 Prieto-Cavareda, Ejército permanente en el año de 1840. Se fija el número de plazas y buques, Santiago, 16 de septiembre de 1839. Anguita, 1912, 331-332.

40 Presupuesto general de sueldos i gastos del departamento del guerra i marina para el año de 1840, con arreglo a las leyes $i$ disposiciones vijentes, Anexo 625, Cámara de Diputados, sesión 27, Santiago, 28 de agosto de 1839 (Letelier, 1902, XXIV, 619-620). Discursos de apertura, 1858a, 413. Memoria que el Ministro del Estado, 1850, 18.
} 
tanto, al menos en términos numéricos la guardia nacional es superior al ejército. Este último, por su parte, enfrenta problemas para llenar las plazas por la inexistencia de una ley de reemplazo que complete y renueve la fuerza de dotación; así lo plantea el ministro Portales en 1831 y lo refrendan sus sucesores en el Ministerio de Guerra en 1835, 1840, 1841, 1843 y $1850 .{ }^{41}$

Ahora bien, las posibilidades del gobierno de Prieto de imponer el orden público se apoyan en la amplia distribución territorial de las milicias. Pero precisa extender y afianzar más aun la cobertura que en 1825 se extiende desde Copiapó por el norte hasta Concepción en el sur. En este sentido, para los primeros años de la administración es clave cubrir y fortalecer puntos neurálgicos como forma de marcar presencia estatal. Por razones políticas, comerciales y defensivas, Santiago, Valparaíso y Concepción, respectivamente, son prioritarios. ${ }^{42} \mathrm{~A}$ mediados de los treinta el aumento de la cobertura es promovido por altas autoridades gubernamentales. En la memoria de la cartera de Guerra de 1835, el ministro José Javier Bustamante señala que para Santiago y muchos pueblos de la república se ha decretado la formación de una «guardia más o menos numerosa, según las circunstancias de cada uno, para atender la seguridad de las cárceles, cuarteles, armamentos» ${ }^{43}$ Dos años más tarde el presidente Prieto reconoce que la extensión progresiva de las milicias hacia las provincias y su servicio activo es un aporte a la Patria. En esta misma línea, Portales sostiene que: «El Gobierno, empeñado en extender esta preciosa institución a todos los pueblos de la República, no creerá haber hecho bastante hasta que cada uno de ellos tenga dentro de sí los medios necesarios para su propia protección». ${ }^{44}$

Esta última afirmación contenida en la Memoria de Guerra del año 1836 no solo recalca la voluntad política de aumentar la cobertura territorial de la guardia nacional sino que advierte sobre su importancia a nivel local, lo que equivale, como se verá más adelante, a resaltar la participación de los vecinos en el mantenimiento del orden público. En definitiva, cada localidad, cada comunidad se hace cargo de su seguridad interna. Tres años más

41 Discursos de apertura, 1858a, 313, 388 y 395. Discursos de apertura, 1858b, 203. Memoria que el Ministro del Estado, 1850, 17.

42 Ovalle, Errázuriz, Guzmán, Meneses, «Milicia Cívica», Santiago 12 de enero de 1830 y «Milicia Cívica», 16 de enero de 1830 (Boletín de las Órdenes, 1831, IV, n. 8, 125-127). Ovalle-Errázuriz, Santiago, 26 de enero de 1830 (Archivo Ministerio de Guerra [AMG], v. 194, n. 4, f. 13). Ovalle-Portales, «Artillería cívica», Santiago, 19 de abril de 1830 (Boletín de las Órdenes, 1831, V, n. 1, 187). Ovalle-Portales, Santiago, 29 de abril de 1830 (AMG, v. 194, n. 23, f. 82). Prieto-Urriola, «Cívicos en Concepción», Santiago, 24 de octubre de 1832 (Boletín de las Órdenes, 1833, V, n. 7, 335).

43 Discursos de apertura, 1858a, 318.

44 Ibidem, 35 y 372. 
tarde el sucesor en la cartera, Ramón de la Cavareda, plantea que se han formado nuevos cuerpos disciplinados y moralizados, tal que «ya cuenta la República en la actualidad con una masa de ciudadanos armados capaces de sostener el orden interior en sus provincias y departamentos». ${ }^{45}$

Como instrumento de orden, la guardia nacional debiera poder incluso reprimir conatos sediciosos de los uniformados de línea. ${ }^{46}$ Pero para ello precisa ser objeto de reconocimiento público y de consenso político, y requiere demostrar que sus hombres están debidamente moralizados para cumplir eficazmente con la función defensiva.

\section{Acuerdos políticos: problema del reconocimiento público y consenso al interior de las elites}

Cuando el ejecutivo confía a la guardia nacional el rol de contrapeso del ejército, en lo inmediato debe convencer a las elites dirigentes de que este reequilibrio de las armas traerá la paz a la República. El fortalecimiento institucional impulsado por el gobierno necesita recursos para financiar gastos operacionales e infraestructura. Pero no es tarea simple porque la imagen pública de las milicias es poco alentadora. A juicio de Encina, en sus más de doscientos años de historia han sido un hacinamiento de hombres indisciplinados, sin armas ni espíritu militar. ${ }^{47}$ ¿Se justifica, entonces, financiar un servicio que históricamente ha tenido un desempeño paupérrimo? El gobierno debe transformar esta aprehensión en aceptación y confianza, persuadiendo a las elites de que es un eficaz «sistema de seguridad nacional», en palabras del presidente Prieto. ${ }^{48}$

La discusión en torno al desarrollo de la institución tiene asidero al interior de las elites porque posiciona el orden público como una urgencia y un valor indiscutible tras la experiencia de la guerra civil. El ejecutivo comprende que la garantía de dicho orden es fundamental para que las elites apoyen la administración pelucona tanto en la opinión pública como en la tribuna parlamentaria. Desde este piso político le es posible conseguir los consensos necesarios para costear el crecimiento y perfeccionamiento de los cuerpos cívicos a lo largo del territorio.

45 Ibidem, 380.

46 Barros Arana, 2005, XVI, 40.

47 Encina, X, 1952, 549.

48 Prieto-Urriola, «Cívicos en Concepción», Santiago, 24 de octubre de 1832 (Boletín de las Órdenes, 1833, V, n. 7, 335). 
La guardia nacional se va posicionando en la discusión pública como una institución tan perfectible como imprescindible. Para visibilizar su labor, logros y lealtad al gobierno el reconocimiento del público es fundamental. Así ocurre a mediados de 1830 cuando el vicepresidente Ovalle felicita a los 200 cívicos que participaron en la expedición pacificadora de Coquimbo contra Freire. El acto se transforma en fiesta pública, en parada militar. ${ }^{49}$ Asimismo, las filas se lucen en las celebraciones patrias del mismo año y del siguiente donde 2.000 hombres rinden honores al presidente Prieto y realizan un simulacro de batalla ante 30.000 personas..$^{50}$

Pero el aplauso público debe trasladarse al Congreso Nacional de plenipotenciarios donde el gobierno introduce en la discusión parlamentaria el financiamiento de la institución. En reconocimiento al desempeño y sacrificio miliciano, en mayo de 1830, el gobierno de Ovalle solicita al Congreso la aprobación de dineros extraordinarios — por un monto de cinco mil pesos chilenos- para vestir a los tres batallones de Santiago. Argumenta que el restablecimiento del orden en la capital responde al comportamiento constante y honrado de estos hombres que dejan de ganarse la subsistencia por cumplir con su deber. ${ }^{51}$ Si bien el Congreso Nacional reconoce los importantes servicios prestados y autoriza la cifra solicitada,${ }^{52}$ el financiamiento está lejos de ser un tema resuelto.

El gobierno continúa con una lógica persuasiva para reforzar las confianzas y expectativas en torno a la guardia nacional. En la apertura del Congreso Nacional de 1831, el ministro Portales señala que: «Los cuerpos cívicos que antes eran masas informes, se hayan en disposición de prestar útiles servicios a la República, por la organización y disciplina a que se les ha sometido»..$^{53} \mathrm{El}$ mensaje tiene repercusiones. Cuatro diputados expresan su admiración por el progreso del servicio, apoyan su masificación gradual, y afirman que su relevancia ha sido consensuada y canalizada por la opinión pública. ${ }^{54}$ Pero los apoyos políticos aun no se materializan en acuerdos legales para costear los gastos de la guardia nacional.

49 Barros Arana, 2005, V, 436.

50 Hernández Ponce, 1984, 82 y 85.

51 Boletín de las Órdenes, 1833, V, n. 6, 323. Ovalle-Portales, Santiago, 3 de mayo de 1830, Anexo 413, Cámara de Senadores, sesión 26, 4 de mayo de 1830 (Letelier, 1897, XVIII, 317).

52 Elizalde-Varas, Santiago, 19 de abril de 1830 (Boletín de las Órdenes, 1831, V, n. 1, 323). Ovalle-Portales, Santiago, 4 de mayo de 1830, cit. en nota anterior.

53 Letelier, 1899, XX, 32.

54 Vial del Río, Astorga y Vial, «Contestación al mensaje del Presidente de la República», Anexo 87, Cámara de Diputados, sesión 5. a, Santiago, 9 de junio de 1831 (Letelier, 1899, XX, 68). 
A mediados de 1833 el ejecutivo solicita al Congreso la aprobación de cien mil pesos chilenos anuales. ${ }^{55}$ Tras discusiones sobre el carácter provincial o nacional del gasto en milicias, por ley del 3 de septiembre del año en curso $^{56}$ el poder legislativo faculta al gobierno para gastar hasta cincuenta mil pesos anuales en armamento, vestuario, cuarteles y música ${ }^{57}$ La medida es fundamental porque el Estado institucionaliza los gastos como nacionales, por lo tanto, costeados por el erario. Pero aun hay dudas sobre la conveniencia de financiar la guardia nacional. Al respecto, en 1835 el ministro de Guerra Bustamante defiende el gasto frente a quienes consideran que los recursos se debieran destinar a «objetos de mayor utilidad», argumentando que no hay fin más importante que la conservación del orden y que no hay un medio más barato para asegurar la tranquilidad pública. ${ }^{58}$

Por su parte, la prensa contribuye notablemente al reconocimiento y credibilidad de la guardia nacional como institución funcional a los objetivos defensivos y políticos del gobierno. En esta línea, El Araucano, principal canal de comunicación de las autoridades peluconas que busca afianzar la idea de orden público y de gobierno fuerte, publica en septiembre de 1831 que los cívicos ya no son agentes de facciones, sino guardianes de la ley, colaboradores del gobierno y moderadores de excesos. ${ }^{59}$

Pero probablemente la impronta personal del ministro Diego Portales en la guardia nacional sea su mejor publicidad. «Al frente de todos los ministerios, Portales supo darse tiempo para dirigir personalmente la nueva organización», señala Encina.$^{60}$ En abril de 1831 se extiende los despachos de teniente coronel y comandante del nuevo batallón número 4 de Santiago ${ }^{61}$ y mantiene el cargo dos años y medio, organizando su cuartel en la Casa de Moneda. ${ }^{62}$ Para cumplir con esta jefatura e igualar el nivel de su

55 Hernández Ponce, 1984, 91-92. «Ministerio de Guerra. Milicia Cívica», Santiago, 3 de septiembre de 1833 (Boletín de las Órdenes, 1834, VI, n. 3, 278).

56 Prieto-Cavareda, «Milicia cívica. Se declara gasto nacional el que cause este servicio», Santiago, 3 de septiembre de 133 (Anguita y Quesney, 1902, 229).

57 Vial del Río, Santiago, 9 de agosto de 1833, Anexo 265, Cámara de Senadores, sesión 19, 10 de agosto de 1833; y sesión 23, 27 de agosto de 1833 (Letelier, 1901, XXI, 527 y 543). Prieto-Cavareda, «Ministerio de Guerra. Milicia Cívica», Santiago, 3 de septiembre de 1833 (Boletín de las Órdenes, 1834, VI, n. 3, 278).

58 Discursos de apertura, 1858a, 316-317.

$85)$.

59 Periódico El Araucano, Santiago, 24 septiembre 1831 (citado en Hernández Ponce, 1984,

60 Encina, 1964, 259.

61 Errázuriz-Portales, «Batallón N4», Santiago, 29 de marzo de 1831 (Boletín de las Órdenes, 1831, V, n. 7, 333-334).

62 Renuncia al cargo el 17 de diciembre de 1833 (Hernández Ponce, 1984, 89). 
batallón con los de línea, estudia táctica militar y el régimen disciplinario del ejército. ${ }^{63}$ Asimismo, en octubre de 1832, mientras ejerce su cargo de gobernador de Valparaíso, ${ }^{64}$ es nombrado comandante en comisión del batallón de infantería y encargado de la organización cuerpos cívicos en el puerto. ${ }^{65}$ A los pocos meses, informa al ministro de Guerra que cuenta con 1.500 hombres, moralizados, subordinados dispuestos a defender al gobierno. ${ }^{66}$ Portales infunde confianza respecto a la guardia nacional a través de dos argumentos: cobertura y disciplina bajo su propio control. Es el hombre con la mayor preponderancia e influencia de la década de 1830; el hombre más poderoso del Estado. En palabras del historiador Isidoro Errázuriz, es el «director omnipotente de la administración y la política». ${ }^{67}$ Por consiguiente, ponerse a sí mismo como rostro visible de la guardia nacional es una efectiva carta de credibilidad frente a las escépticas elites.

Por último, lo que resta para conseguir mayores acuerdos legales es que la guardia nacional exhiba resultados que justifiquen el gasto del erario. Debe mostrar en hechos, su compromiso político y capacidad militar. ${ }^{68}$ En esta línea, la operación conjunta de militares y cívicos que derrota a la banda de los Pincheira en 1832 contribuye a la mayor estima de la opinión pública. En suma, la institución será objeto de consenso político en la medida que demuestre ser sujeto de confianzas para las elites dirigentes. La moralización de los cuerpos cívicos es una herramienta fundamental para aumentar dichas confianzas.

\section{Función moralizadora: problema de la eficacia militar de los cuerpos cívicos}

Durante el siglo XIX la moralización está estrechamente vinculada a la imposición de la ley, instrumento de progreso material e inmaterial, que «encierra en sí el germen de una perfección indefinida». ${ }^{69}$ Pero el ministro

63 Sotomayor Valdés, 1954, 58.

64 El 4 de diciembre de 1832 Portales es designado gobernador interino del departamento de Valparaíso (Sotomayor Valdés, 1962, 328).

65 Prieto-Urriola, «Cívicos en Concepción», Santiago, 24 de octubre de 1832 y «Comandante de Cívicos», 25 de octubre de 1832 (Boletín de las Órdenes, 1833, V, 335, 336).

66 Carta de Diego Portales a Ramón de la Cavareda, Valparaíso, 7 de marzo de 1833 (Fariña, 2007, II, 387-388).

67 Errázuriz, 1935, 171.

68 Barros Arana, 2005, XVI, 40.

69 Constitución de 1828, en Valencia Avaria, 1986, I, 150. 
Portales es escéptico de esta sacralización y efectividad de las leyes. ${ }^{70}$ Tampoco cree en la educación como medio moralizador, la descarta por su lentitud, acceso restringido y focalización en niños y no en adultos. ${ }^{71}$ Desde su sitial privilegiado en el gobierno impone una moralización inmediata y concreta para corregir a la plebe, catalogada en el arraigado imaginario de las elites como indecente, ignorante y ociosa.

$\mathrm{Si}$ bien el gobierno considera a la plebe moralmente inferior, ${ }^{72}$ solo puede reclutar la tropa entre campesinos y artesanos porque no hay más hombres «disponibles» para cargar armas, y solo puede nombrar para su mando a la «gente decente». Tanto la historiografía clásica liberal como la conservadora subrayan la función moralizadora que se auto-arrogan las elites. En este contexto se debe entender el rol que Barros Arana y Sotomayor Valdés asignan a la guardia nacional: «medio de proporcionar al pueblo una distracción que lo apartase de las tabernas y del vicio en los días festivos» $\mathrm{y}$ «medio de moralidad para un pueblo cuya índole y costumbres [Portales] conocía profundamente», ${ }^{73}$ respectivamente.

Pero a diferencia de los autores recién citados, aquí se plantea que la intención del gobierno no es tanto sacar a la plebe de los vicios, como asegurar un contingente de hombres para el funcionamiento de la guardia nacional. Como el populacho que tanto se desprecia es la única alternativa para organizar las tropas, la solución alentada por Portales es moralizarlo para asegurar su credibilidad y subordinación como grupo armado. Procura moralizar mediante disciplina militar dirigida por uniformados, pero encauzada a través de jerarquías sociales, es decir, vía dominación social, como se verá en el siguiente apartado. El propósito es lograr la mayor adhesión a las autoridades constituidas, reduciendo el riesgo de desobediencia y disidencia. En suma, la finalidad primera de la moralización es la instrucción para servir de dique de contención, pero la última es la adhesión política al gobierno.

El cuartel es el espacio para moralizar a la tropa. En este contexto, moralizar es disciplinar; moldear el comportamiento con órdenes y castigos que cercioren el cumplimiento de deberes militares y lealtades políticas.

70 Portales advierte que el problema no son las leyes en sí mismas, sino los encargados de velar por su adecuada aplicación. Los jueces no hacen bien el trabajo, no garantizan la correcta y oportuna sanción de penas y castigos. Carta de Diego Portales a Antonio Garfias, Valparaíso, 6 de diciembre de 1834 (Fariña, 2007, II, 589-590).

71 Sotomayor Valdés, 1954, 57.

72 Araya Espinoza, 1999, 18.

73 Barros Arana, 2005, XV, 436. Sotomayor Valdés, 1954, 57. 
Según Sotomayor Valdés, el sentido de pertenencia colabora a este objetivo ya que el cívico se identifica con un cuerpo, un uniforme, y un jefe que lo instruye y al cual debe total obediencia. ${ }^{74} \mathrm{El}$ entrenamiento es primordial para contrapesar las filas castrenses. Por este motivo, Portales releva la instrucción de la guardia nacional con diversas medidas. Primero, insiste en la separación de la comandancia general de armas de la inspección del ejército. ${ }^{75}$ Segundo, con el objeto de depurar el ejército, rehabilita la academia militar, orientada a jóvenes de familias decentes, a cargo — entre otras funciones- de la instrucción de cívicos. ${ }^{76}$ Tercero, establece la obligatoriedad de ejercicios militares en todo el territorio los días domingo para no interferir en las actividades productivas y laborales; toma la precaución de no entorpecer la misa dominical ni la cosecha de verano para evitar problemas con la iglesia y con los hacendados. ${ }^{77}$ Cuarto, incentiva la música como herramienta disciplinaria porque aleja de distracciones groseras. Su especial interés por formar bandas de músicos comienza con la dotación de instrumentos al batallón número 4 , bajo su mando. ${ }^{78}$

De esta manera, se formaliza y organiza el contingente cívico sobre una ancha base disciplinada. ${ }^{79}$ Para las autoridades peluconas, la ampliación de la cobertura de tropas moralizadas colabora con el orden institucional estatal. En el discurso anual de 1835 leído frente al Congreso Nacional, el presidente Prieto asegura que: «La disciplina de los cuerpos cívicos, y la extensión que se les da sucesivamente en las provincias, fundamentos indestructibles de la independencia de Chile y la estabilidad de nuestras instituciones republicanas». ${ }^{80}$ En el mismo año el ministro de Guerra Bustamante se jacta de que la «milicia es una masa arreglada por las ordenanzas generales del ejército» Agrega que los cívicos de Santiago están en «tan buen estado de disciplina que, en cualquier caso, con pocos días de campaña o cuar-

74 Sotomayor Valdés, 1954, 57.

75 Ovalle-Portales, Santiago, 19 de abril de 1830; «Inspección Jeneral del Ejército», Santiago, 11 de septiembre de 1830, AMG, v. 194, f. 77. Varas, 1870, 385. Mientras a la comandancia general le compete la movilización y logística de las tropas, a la inspección le corresponde la organización y funcionamiento interno de los cuerpos (disciplina, moral y orden contable).

76 La academia o escuela militar es fundada por O'Higgins en 1817, pero cerrada dos años después. Sotomayor Valdés, 1962, 333.

77 «Guardias Cívicas», Santiago, 31 de octubre de 1836 (Boletín de las Órdenes, 1837, VII, n. $5,445-446)$.

78 Zapiola Cortés, 1974, 54. Sobre el valor estratégico de la música para Portales ver: Cartas de Diego Portales a Antonio Garfias, s/l, 20 agosto de 1833 y Valparaíso, 15 de junio 1834 (Fariña, 2007, II, 418-419 y 463-464, respectivamente), y Encina, 1964, 259-260.

79 De la Cruz, 1936, 58.

80 Discursos de apertura, 1858a, 24. 
tel, podían hacer las fatigas y servicio de los veteranos». ${ }^{81}$ La comparación entre ambas fuerzas es un recurso recurrente para justificar las decisiones políticas que apuestan a la guardia nacional como antemural del ejército.

Contar con una tropa moralizada es la base mínima de confianzas entre el comandante del cuerpo y las autoridades de gobierno. Por lo tanto, la violencia que cae sobre los cívicos en aras de la moralización - tan criticada por la historiografía liberal contemporánea- ${ }^{82}$ estaría plenamente justificada para un Portales que no duda de la eficacia del «palo y el bizcochuelo, justa y oportunamente administrado» como mecanismo capaz de enderezar a la plebe. ${ }^{83}$ Pero los palos y azotes no son el único medio para asegurar la obediencia, ni menos el más efectivo. La subordinación de los soldados no se sustenta únicamente en la fuerza directa, sino en el empalme de jerarquías cívicas y sociales. En la tradición miliciana la figura del comandante es clave en dicha articulación. De allí que la cobertura, el consenso político y la moralización, no sirvan de nada si el gobierno no cuenta con jefes cívicos confiables distribuidos a lo largo del territorio que canalicen las instrucciones y objetivos del gobierno.

\section{Mecanismo sociopolítico y territorial: problema de la confiabilidad y legitimidad de la guardia nacional}

En los años treinta el Estado chileno necesita marcar presencia en territorios amplios, dispersos y aislados. La administración pelucona debe enfrentar el problema geográfico y político de cómo gobernar espacios y habitantes alejados del poder central. A comienzos de la década, la autonomía provincial de los veinte demuestra que aun puede ser un peligro para el gobierno pelucón. ${ }^{84}$ En conformidad, la carta de 1833 elimina las asambleas como estructuras políticas y de representatividad local, sancionadas constitucionalmente desde 1823. A diferencia de sus predecesoras, no contempla

81 Ibidem, 1858a, 319.

82 Villalobos, 1989, 152. Salazar, 1991, 220. Grez Toso, 1997, 277.

83 Carta de Diego Portales a Fernando Urízar Garfias, Santiago, 1. ${ }^{\circ}$ de abril de 1837 (Fariña, II, 2007, 676-677).

84 La provincia descansa en una asamblea sancionada en la constitución moralista de 1823 y luego en la liberal de 1828. Pero para evitar que las provincias caigan en «turbulencias peligrosas» este último texto limita su accionar. Aunque la asamblea pierde la facultad de legislar y dictar constituciones, la autonomía provincial sigue dando problemas al gobierno central. En febrero de 1830 la provincia de Aconcagua declara su independencia frente a la capital y su decisión de elegir una asamblea constituyente, siendo sofocada por el gobierno de Ovalle. Constitución de 1828, en Valencia Avaria, 1986, I, 152. Barros Arana, 2005, XV, 365. 
atribuciones para las organizaciones locales precisamente porque los recursos e influencias de sus actores pueden ser desestabilizadores.

Si bien las comunidades pierden peso constitucional y status político administrativo, las jerarquías sociopolíticas locales siguen intactas. Pero dichos poderes no son un problema para la administración de Prieto, al contrario su avenencia es necesaria para reactivar los resortes de las antiguas milicias. En este sentido, más allá de la exclusión constitucional, el gobierno reconoce el papel estratégico de las localidades como espacios socialmente jerarquizados. Así lo indica el nombramiento de comandantes entre ciudadanos, a saber, vecinos distinguidos y respetables, de «notoria calidad». Son funcionales a un Estado precario - de recursos escasos y burocracia limitada - que requiere administrar y controlar sus territorios, específicamente, que debe garantizar la paz tras un periodo de desorden institucional y guerra interna. El gobierno refuerza, entonces, la guardia nacional como instrumento de orden público sobre la base de una distribución masiva y territorial de las armas en manos de poderosos locales confiables. La masificación del servicio es impensable sin la confianza en los ciudadanos y en su expectativa de colaboración en la prosecución de una tranquilidad pública compartida. ${ }^{85}$

El problema de la confianza no es solo político sino social. Desde las primeras milicias del reino de Chile la autoridad social sirve de pivote para la autoridad al interior de los cuerpos, en otras palabras, las jerarquías milicianas se sostienen sobre jerarquías sociales. De esta manera los sectores decentes asumen la comandancia y oficialidad, mientras que la tropa es reclutada entre campesinos y artesanos, reproduciendo las diferencias sociales al interior de los cuarteles. ${ }^{86}$ En términos de Max Weber, la autoridad del jefe cívico se legitima en la tradición, ${ }^{87}$ en la forma de vínculo social patronal entre hacendado e inquilinos, verticalidad que se extiende a la relación entre comerciantes y dependientes. Además, a través de las milicias los rangos sociales son investidos con cargos militares que refuerzan la distinción social en la medida que la graduación miliciana se equipara a la veterana. Precisamente, dicha transmisión de prerrogativas, códigos y símbolos militares explican el reconocimiento social que aun tiene la

85 Ovalle-Portales, Santiago, 29 de abril de 1830, AMG, v. 194, n. 23, f. 82.

86 Barros Arana, 2005, XV, 436. Edwards, 1972, 111. Nunn, 1976, 41.

87 En la dominación tradicional la autoridad se legitima en la fe en la rutina cotidiana como norma de conducta inviolable. Su fundamento de legitimidad está en la santidad de las normas y poderes de mando heredados de tiempo inmemorial. Weber, 1998, 180. 
oficialidad y comandancia miliciana a mediados del siglo XIX. ${ }^{88}$ Mientras la historiografía tradicional constata la conveniencia de esta convergencia que refleja las tradiciones sociales que cuadra «el espíritu general del país», la mirada contemporánea liberal es crítica. La moralización impulsada por Portales no sería más que un instrumento de dominación en los cuarteles, señala Gabriel Salazar; ${ }^{89}$ una forma de «sujeción pasiva de los pobres a la jerarquía militar, al orden social y al poder político», agrega Grez Toso. ${ }^{90}$ Más allá de las interpretaciones historiográficas, lo cierto es que en este empalme de jerarquías radica la confiabilidad y legitimidad del servicio porque se trata de un mecanismo de seguridad conocido y probado en el tiempo, basado en la dominación social.

Pero más allá de la explicación weberiana sobre la legitimidad de un tipo de autoridad basada en la tradición, en este caso, arraigado en la estructura rural patronal y alentado por el simbolismo militar, ¿por qué tal dominación que alcanza ribetes de autoritarismo social mantiene un status incólume en el tiempo sin mayores cuestionamientos? ¿Es mera reproducción de la tradición lo que explica el empalme de jerarquías sociales y cívicas o hay algo más? Probablemente sea el propio ministro Portales quien mejor se acerque a la respuesta. En una célebre carta de 1832 escribe lo siguiente: «El orden social se mantiene en Chile por el peso de la noche porque no tenemos hombres sutiles, hábiles y cosquillosos: la tendencia casi general de la masa al reposo es la garantía de la tranquilidad pública. Si ella faltase, nos encontraríamos a obscuras y sin poder contener a los díscolos más que con medidas dictadas por la razón, o que la experiencia ha enseñado a ser útiles». ${ }^{91}$

Con estas palabras establece que el orden social se conserva porque no existe una alternativa racional ilustrada, a saber, hombres sutiles, hábiles y cosquillosos que pudieran cuestionar y luego cambiar dicha estructura social; en términos de Alfredo Jocelyn-Holt porque no existe un orden liberal que critique este orden social fáctico. ${ }^{92}$ El resultado es el mantenimiento del statu quo garantizado por el reposo de la masa, a saber, la sumisión, docilidad y obediencia que consagra las jerarquías sociales, y que muy bien colabora a la reproducción de la guardia nacional como un servicio que naturaliza las diferencias y desigualdades sociales.

88 Góngora, 1970, 99-100, y 1975, 428. Salazar, 2005, 439.

89 Salazar, 1991.

90 Grez Toso, 1997, 277.

91 Carta de Diego Portales a Joaquín Tocornal, Valparaíso, 16 de julio de 1832 (Fariña, 2007, I, 287-288).

92 Jocelyn-Holt, 1997, 150-151. 
Ahora bien, a fines de los años veinte las elites todavía ven con reticencia la militarización masiva de quienes consideran inferiores. En 1831, durante la gran convención de reforma a la constitución de 1828 se retoma el viejo temor de armar al populacho: «¿Cómo formar la milicia nacional sin que vuelva las armas contra su gobierno?». ${ }^{93}$ El peligro de entregar el fusil a la plebe se resuelve asegurando su control al jefe cívico, cuya autoridad no es tanto militar como social. La «gente decente» solo confía en milicias previamente organizadas, jerarquizadas y dirigidas por hombres de su misma categoría social, observa Fernández Abara. ${ }^{94}$ De allí la celosa selección de oficiales y comandantes de la guardia nacional que bien grafica el ministro de Guerra Bustamante en la memoria del ramo de 1835: «El Gobierno tiene sumo cuidado de que la fuerza cívica sea mandada por jefes, cuyo carácter, honradez y fortuna presten una garantía al orden». El documento agrega que la confianza del gobierno en la institución descansa en «bases sólidas y prudentes» porque las jefaturas son designadas a «hombres ilustrados y de sana razón». La adecuada designación de comandantes augura una fuerza bien arreglada y útil al ejecutivo. ${ }^{95}$ Así, más que una efectiva masificación, adecuada instrucción y suficiente financiamiento, es la decencia dada por origen familiar, prestigio local, riqueza y propiedad la garantía primera del orden público. Ello explica por qué en 1843 el gobierno del presidente Manuel Bulnes (1841-1851) decide nombrar con el cargo de coronel de escuadrones en zonas rurales, a «uno de los propietarios de más nota del distrito militar». ${ }^{96}$

El nombramiento de comandantes presupone entonces altas cuotas de confianza que, en las primeras décadas del siglo XIX, está ligada a la decencia de los vecinos y sus familias. En Hispanoamérica en general y en Chile en particular, el concepto de ciudadanía de las primeras décadas republicanas aun tiene resabios del antiguo concepto de vecino que versa sobre la pertenencia (a un territorio, estamento, cuerpo). Ser vecino es más que ser habitante de un territorio, es ser poseedor de estatutos al interior de una comunidad política - la ciudad - que otorgan privilegios, franquicias y exenciones ${ }^{97}$ Dado que el vecino es siempre un hombre concreto, territorializado, enraizado», ${ }^{98}$ su notoriedad está dada por el reconocimiento de la

93 «Un proyecto de reforma a la parte $6^{\mathrm{a}}$ el artículo 83 de nuestra Constitución», Artículos relativos a los trabajos de la Comisión de formular un proyecto de la Constitución y otras materias, Anexo 10, Gran Convención, sesión 4. a, Santiago, 25 de octubre de 1831 (Letelier, 1901, XXI, 16).

94 Fernández Abara, 2004.

95 Discursos de apertura, 1858a, 316.

96 Discursos de apertura, 1858b, 205.

97 Sobre el concepto antiguo de vecino en Chile ver Góngora 1970 y 1975.

98 Guerra, 1999, 42. 
comunidad que respeta a quienes tienen un modo honesto de vivir. ${ }^{99}$ Pero la decencia no refiere solamente a la extracción social, sino a cómo cada cual reconfirma y representa su relevancia social. En efecto, «lo más representativo de una comunidad política es su parte más sana: mejor, más distinguida, su sanior pars, melior pars o valentior pars». ${ }^{100}$ Por consiguiente, criterios como «moralidad intachable», «patriotismo», «adherencia al orden», «miembro de familia distinguida», «origen familiar prestigioso», «vecino respetable» son los fundamentales para cerciorar que el comandante represente adecuadamente los intereses del gobierno y los de su comunidad. Se trata entonces de una doble representación, en este caso, en aras del objetivo común del orden público.

En cuanto a la representación de intereses sociales y políticos, el historiador francés Pierre Rosanvallon plantea dos principios. El «principio de la semejanza» se sostiene en la demanda social que los elegidos hacen a sus pares, es decir, a sus iguales; buscan en el representante la proximidad y el parecido. El «principio de la diferencia», en cambio, enfatiza las capacidades y la experticia. Cuando prima este último, el conocimiento del funcionamiento social da al representante las herramientas para responder a las demandas. En cambio, bajo el primero la experiencia comunitaria entre representante y representado es lo fundamental. Los vínculos sociales mueven los mecanismos de esta representación inmediata. Aquellos que pertenecen a los estamentos privilegiados se encargan de mostrar públicamente quiénes son y quiénes constituyen su círculo. La manera más evidente y directa de representarse es a través de un otro igual. ${ }^{101}$

Pero la representación no se agota en la elección. ${ }^{102}$ Tal característica de sociedades de antiguo régimen aun se mantiene en el Chile decimonónico. La mayoría de los cargos no son elegidos, sino designados según criterios tradicionales como status moral y buenas costumbres. La representación inmediata no se pide, ni se rechaza; se recibe y acepta. ${ }^{103}$ Se trata del reconocimiento público del «principio de semejanza»: las elites dirigentes solo ponen a los suyos en cargos de confianza, quienes no se pueden negar a representar a sus iguales. Estas prácticas políticas se observan precisamente en los nombramientos de comandantes y oficiales de la guardia nacional. Miembros de las elites deben ocupar los altos mandos cívicos porque está

99 Annino, 1999, 68.

100 Bravo Lira, 1991, 62.

101 Rosanvallon, 2004-2005, 453-454.

102 Guerra, 1998, 138.

103 Lempérière, 1998, 55. 
en sus manos reproducir las relaciones de desigualdad al interior de los cuarteles como una arista más del orden social que es preciso mantener. De esta manera, las diferencias estamentales se representan de manera inmediata, sin intermediación procedimental.

Con todo, obligaciones formales sancionadas constitucionalmente, compromisos políticos, lealtades personales y lógicas locales convergen en un punto: el despacho de nombramiento para comandante de la guardia nacional. Este instrumento burocrático formaliza la doble representación: como miembro de la elite dirigente el jefe cívico representa los intereses políticos y defensivos del gobierno, y como miembro de la comunidad representa los intereses de los poderosos locales. A través del despacho las autoridades gubernamentales se aseguran de un contingente armado confiable, y la comunidad del resguardo del orden público local. Ambos se juegan sus cartas en la figura del comandante. La doble representación se cierra en el privilegio honorífico que da ser un hombre de confianza del presidente de la república, investido con títulos militares, altamente valorados por la elite chilena como criterio de distinción social. ${ }^{104}$

En suma, solo los mejores hombres, solo aquellos que tienen la capacidad para gobernar y mandar, la distinción económica, política y social para estructurar un orden jerárquico deben vestir uniforme cívico y guiar tropas en aras del orden público. El peso de la noche al que refiere Portales, aseguraría, precisamente, que los mejores hombres sean los que deben ser, a saber, los que están en la cúspide de las jerarquías. No es pensable ni plausible que sean otros; no están dadas ni son esperables condiciones que cambien esta selección natural. Al respecto, el ministro de Guerra José Santiago Aldunate se refiere en 1844 a la importancia de salvaguardar este principio, cerciorando la calidad del comandante: «Sin duda que la empresa de organizar la Guardia cívica envuelve cuestiones de alto interés social porque la milicia es y será en lo venidero un cuerpo muy influyente en nuestra suerte política y conviene saber en qué manos habrán de depositarse los resortes que la mueven». ${ }^{105}$

De sus palabras se desprende que no cualquiera puede representar al gobierno y a las elites locales porque está en juego la distribución masiva de las armas en los territorios de la República para salvaguardar, precisamente, el orden público que favorece a los poderosos.

104 Valenzuela, 2005, 77.

105 Discursos de apertura, 1858b, 316-317. 


\section{Conclusión}

El funcionamiento y posicionamiento de la guardia nacional como «recurso de seguridad» incluye pero trasciende la voluntad y gestión política del gobierno de Prieto y de su ministro Portales. Es parte de un entramado sociopolítico propio de las localidades que ordena jerárquicamente los territorios, al margen de la institucionalidad estatal. Es más, el Estado al apoyarse en este antiguo mecanismo reconoce sus propias debilidades y releva la fortaleza de las dinámicas y estructuras sociales, de las cuales, quiéralo o no depende para asegurar el orden público.

El gobierno de Prieto observa y actúa; preserva e innova. Primero, quita poderes fácticos a un ejército revoltoso y fragmentado, poniendo como antemural a un contingente masivo de hombres, sin mayor preparación ni entrenamiento, pero bajo un jefe cívico designado por el presidente de la república para comandarlo en su función defensiva. Segundo, comprende que sin el apoyo político de las elites la guardia nacional no tiene posibilidad alguna de desarrollo. Es preciso convencer a la opinión pública y a la tribuna parlamentaria que la institución contribuye a la recuperación de la tranquilidad pública perdida en la crisis de 1829. Sin este reconocimiento básico no es posible el consenso político necesario para legalizar el financiamiento. Tercero, la guardia nacional debe evidenciar que sus hombres tienen la destreza y disciplina militar suficiente para servir de contrapeso ante eventuales levantamientos de los uniformados de línea. Solo tropas moralizadas y comprometidas con el gobierno pueden transformar la deplorable imagen que se tiene de las antiguas milicias, contribuyendo a su credibilidad como fuerza de orden eficaz. Cuarto, conserva el pilar de las antiguas milicias y asume la relevancia sociopolítica del territorio, depositando el vínculo de mando y obediencia en jerarquías milicianas que empalman con jerarquías sociales sancionadas por la tradición. Allí radica la eficacia de la guardia nacional. Este dispositivo a pequeña escala de gestión de las armas se multiplica territorialmente porque es confiable y goza de legitimidad.

En suma, el ejecutivo considera el deber de cargar armas, internalizado en la población por siglos, para innovar. Las milicias dan paso a una institución con más batallones, escuadrones y brigadas. Pero no se trata solo de masificar, sino de centralizar el servicio. Aumenta la cobertura con cuerpos mejor instruidos y disciplinados, bajo el mando de jefes que actúan como punto de anclaje del gobierno en la localidad. Los poderosos 
locales colaboran con la función estatal de garantizar el orden público porque también es útil a los intereses de la comunidad que representa. Solo así la guardia nacional puede cubrir las necesidades de seguridad de los territorios y tener alcance nacional. Solo así el poder central puede «llegar» e «instalarse» en las localidades. Solo así el Estado puede centralizarse. En la época centralizar implica principalmente marcar presencia en territorios aislados y distanciados, pese a sus insuficiencias institucionales. Al relevar el rol de la guardia nacional en 1841, el ministro de Guerra subrogante Manuel Montt da cuenta de dicha precariedad burocrática estatal: «auxiliar poderoso de las autoridades civiles y judiciales, ya sea en las poblaciones, ya sea en los campos, en donde por la imperfección de nuestro sistema gubernativo, la mayor parte de los funcionarios carecen de recursos para cumplir debidamente sus deberes». ${ }^{106}$

En este escenario el gobierno articula la única forma que un Estado precario tiene para mantener la seguridad interna: asumir las debilidades institucionales, reconocer el peso sociopolítico de las localidades, aprovechando la fortaleza de vínculos sociales legitimados para cumplir con objetivos estatales. Así, durante las primeras décadas del siglo XIX, la centralización del orden público en los territorios es una función compartida y no exclusiva del Estado chileno, que es una institución todavía en proceso de construcción que requiere la colaboración de los poderes locales porque aun no tiene la autosuficiencia burocrática ni la capacidad de monopolizar la violencia.

Recibido el 13 de octubre de 2015

Aceptado el 18 de mayo de 2016

\section{Referencias bibliográficas}

Anguita, Ricardo (comp.), Leyes promulgadas en Chile desde 1810 hasta el $1^{\circ}$ de junio de 1912, Santiago, Imprenta, Litografía y Encuadernación Barcelona, 1912 , v. 1.

Anguita, Ricardo y Quesney, Valerio (comps.), Leyes promulgadas en Chile desde 1810 hasta 1901 inclusive, Santiago, Imprenta Nacional, 1902.

Annino, Antonio, «Ciudadanía "versus" gobernabilidad republicana en México», en Sábato, Hilda (coord.), Ciudadanía política y formación de las naciones.

106 Discursos de apertura, 1858a, 316-317. 
Perspectivas históricas de América Latina, México, El Colegio de México, Fidecomiso Historia de las Américas, Fondo de Cultura Económica, 1999, 62-93.

Araya Espinoza, Alejandra, Ociosos, vagabundos y malentretenidos en Chile Colonial, Santiago, DIBAM, LOM y Centro de Investigaciones Diego Barros Arana, 1999.

Barros Arana, Diego, Historia General de Chile, Santiago, Editorial Universitaria, Centro de Investigaciones Diego Barros Arana, 2005, Tomos VI, VII, XV, XVI.

Boletín de las Órdenes, Decretos y Leyes Nacionales, Libros IV, VI y VII, Santiago, Imprenta de la Independencia, 1831-1837.

Brahms García, Enrique, Mariano Egaña. Derecho y política en la fundación de la república conservadora, Santiago, Centro de Estudios Bicentenario, 2007.

Bravo Lira, Bernardino, «Portales y el tránsito al Absolutismo ilustrado», en Bravo Lira, Bernardino (comp.), Portales, el hombre, y su obra. La consolidación del gobierno civil, Santiago, Editorial Jurídica, Editorial Andrés Bello, 1989, 321-441.

Bravo Lira, Bernardino, «Comunidad política y representación del pueblo en Chile. De la Conquista a la Ilustración, 1541-1760», Revista de Estudios Históricos Jurídicos, 14, Valparaíso, 1991, 57-100.

De la Cruz, Ernesto (comp.), Epistolario de don Diego Portales 1821-1837, Santiago, Ministerio de Justicia, 1936.

Discursos de apertura en las sesiones del Congreso. Memorias Ministeriales correspondientes a la administración Prieto (1831-1841), Santiago, Imprenta del Ferrocarril, 1858a.

Discursos de apertura en las sesiones del Congreso y Memorias ministeriales correspondientes al primer quinquenio de la administración Bulnes (18421846), Santiago, Imprenta del Ferrocarril, 1858b.

Edwards, Alberto, La organización política de Chile, Santiago, Editorial del Pacífico, 1972.

Edwards, Alberto, La fronda aristocrática en Chile, Santiago, Editorial Universitaria. 1982.

Encina, Francisco A., Historia de Chile. Desde la prehistoria hasta 1891, Santiago, Editorial Nascimento, 1952, tomo V.

Encina, Francisco A., Portales, 2. ${ }^{a}$ ed., Santiago, Editorial Nascimento, 1964, tomo I.

Errázuriz, Isidoro, Historia de la administración Errázuriz: precedida de una introducción que contiene la reseña del movimiento y la lucha de partidos desde 1823 hasta 1871, Santiago, Imprenta Dirección de Prisiones, 1935.

Fariña, Carmen (ed.), Epistolario Diego Portales (1821-1837), Santiago, Ediciones Universidad Diego Portales, 2007, 2 vols. 
Fernández Abara, Joaquín, «Los orígenes de la Guardia Nacional y la construcción del ciudadano soldado (Chile, 1823-1833)», Mapocho Revista de Humanidades, 56, Santiago, 2004, 313-327.

Fernández Abara, Joaquín, «¿Pueblo en armas o juguetes del poder? La Guardia Nacional y la formación de la identidad nacional en los sectores populares en Chile, 1830-1846», ponencia presentada en las Segundas Jornadas de Historia Social en reconocimiento a Luis Vitale Cometa, Santiago de Chile, 29-30 de septiembre de 2005.

Góngora, Mario, El Estado en el Derecho indiano. Época de fundación 1492-1570, Santiago, Universidad de Chile, 1951.

Góngora, Mario, Encomenderos y estancieros. Estudios acerca de la Constitución social aristocrática de Chile después de la Conquista 1560-1660, Santiago, Universidad de Chile, 1970.

Góngora, Mario, «Urban Social Stratification in Colonial Chile», The Hispanic American Historical Review, 55-3, 1975, 421-448, http://www.jstor.org/ stable/2512374 [Consultado: 22/04/2012].

Góngora, Mario, Ensayo histórico sobre la noción de estado en Chile en los siglos XIX y XX, Santiago, Editorial Universitaria, 1986.

Grez Toso, Sergio, De la «regeneración del pueblo» a la huelga general. Génesis y evolución histórica del movimiento popular en Chile (1810-1890), Santiago, DIBAM, RIL, Centro de Investigaciones Diego Barros Arana, 1997.

Guerra, François-Xavier, «De la política antigua a la política moderna. La revolución de la soberanía», en Guerra, François-Xavier y Lempérière, Annick (coords.), Los espacios públicos en Iberoamérica. Ambigüedades y problemas, siglos XVIII-XIX, México, Centro Francés de Estudios, 1998, 109-139.

Guerra, François-Xavier, «El soberano y su reino. Reflexiones sobre la génesis del ciudadano en América Latina», en Sábato, Hilda (coord.), Ciudadanía política y formación de las naciones. Perspectivas históricas de América Latina, México, El Colegio de México, Fidecomiso Historia de las Américas, Fondo de Cultura Económica, 1999, 33-93.

Heise González, Julio, Años de formación y aprendizaje políticos. 1810-1833, Santiago, Editorial Universitaria, 1978.

Hernández Ponce, Roberto, «La Guardia Nacional de Chile. Apuntes sobre su origen y organización, 1808-1848», Historia, 19, Santiago, 1984, 53-114.

Jara, Álvaro, Guerra y sociedad en Chile. La transformación de Arauco y la esclavitud de los indios, Santiago, Editorial Universitaria, 1971.

Jocelyn-Holt, Alfredo, El peso de la noche. Nuestra frágil fortaleza histórica, Santiago, Editorial Planeta, Ariel, 1997.

Lempérière, Annick, «República y publicidad en el Antiguo Régimen», en Guerra, François-Xavier y Lempérière, Annick (coords.), Los espacios públicos en Iberoamérica. Ambigüedades y problemas, siglos XVIII-XIX, México, Centro Francés de Estudios, 1998, 54-79. 
Letelier, Valentín (comp.), Sesiones de los Cuerpos Lejislativos de la República de Chile. 1811 a 1845, tomos XII, XVIII, XX, XXI y XXIV, Santiago, Imprenta Cervantes, 1889-1902.

Memoria que el Ministro del Estado en el Departamento de Guerra presenta al Congreso Nacional de 1850, Santiago, Imprenta de Julio Belin y Cia., 1850.

Nunn, Frederick M., The Military in Chilean History. Essays on Civil-Military Relations, 1810-1973, Albuquerque, University of New Mexico Press, 1976.

Oñat, Roberto y Roa, Carlos, Régimen legal del ejército en el reino de Chile. Notas para su estudio, Santiago, Estudios de Historia del Derecho Chileno, 1, Universidad Católica de Chile, 1953.

Pinto Vallejos, Julio y Valdivia Ortiz de Zárate, Verónica, ¿Chilenos todos? La construcción social de la nación (1810-1840), Santiago, LOM Ediciones, 2009.

Rosanvallon, Pierre, «Cours Les dilemmes de la démocratie», en Histoire moderne et contemporaine du politique, Paris, College de France, 2004-2005, 453461, http://www.college-de-france.fr/media/pierre-rosanvallon/UPL28687_ UPL19784_rosanvallonres0405.pdf [Consultado: 08/03/2008].

Salazar, Gabriel, «Empresario popular e industrialización: la guerrilla de los mercaderes (Chile, 1830-1885)», Proposiciones, 20, Santiago, 1991, 180-231.

Salazar, Gabriel, Construcción de Estado en Chile (1800-1837). Democracia de los «pueblos». Militarismo ciudadano. Golpismo oligárquico, Santiago, Editorial Sudamericana, 2005.

Stuven, Ana María, «Una aproximación a la cultura política de la elite chilena: concepto y valoración del orden social (1830-1860)», Estudios Públicos, 66, Santiago, 1997, 259-311.

Stuven, Ana María, La seducción de un orden. Las elites y la construcción de Chile en las polémicas culturales y políticas del siglo XIX, Santiago, Ediciones Universidad Católica, 2000.

Sotomayor Valdés, Ramón, El ministro Portales, Santiago, Ministerio de Educación Pública, 1954.

Sotomayor Valdés, Ramón, Historia de Chile bajo el gobierno del general don Joaquín Prieto, Santiago, Fondo Histórico Presidente Joaquín Prieto, 1962, tomo I.

Valencia Avaria, Luis (comp.), Anales de la República, Santiago, Editorial Andrés Bello, 1986, tomo I.

Valenzuela, Jaime, «Afán de prestigio y movilidad social: los espejos de la apariencia», en Sagredo, Rafael y Gazmuri, Cristián (eds.), Historia de la vida privada en Chile. El Chile tradicional. De la Conquista a 1840, Santiago, Editorial Taurus, 2005, 71-93.

Varas, José Antonio (comp.), Recopilación de leyes, decretos supremos i circulares concernientes al Ejército, desde abril de 1812 a diciembre de 1839, Santiago, Imprenta Chilena, 1870, tomo I. 


\section{MARÍA TERESA DOUZET CARAFÍ}

Vergara Quiroz, Sergio, «Portales y el Ejército», en Bravo Lira, Bernardino (comp.), Portales, el hombre y su obra. La consolidación del gobierno civil, Santiago, Editorial Andrés Bello, 1989, 87-116.

Villalobos, Sergio, Portales. Una falsificación histórica, Santiago, Editorial Universitaria, 1989.

Weber, Max, Economía y Sociedad, México, Fondo de Cultura Económica, 1998.

Zapiola Cortés, José, Recuerdos de treinta años (1810-1840), Buenos Aires/Santiago, Editorial Francisco de Aguirre, 1974. 